\title{
Results from a magnetic survey and geomagnetic depth sounding in the post-eruption phase of the Barren Island volcano
}

\author{
B. Banerjee ${ }^{1}$, P. B. V. Subba Rao ${ }^{2}$, Gautam Gupta ${ }^{2}$, E. J. Joseph ${ }^{2}$, and B. P. Singh ${ }^{2}$ \\ ${ }^{1}$ Marine Wing, Geological Survey of India, Calcutta 700 016, India \\ ${ }^{2}$ Indian Institute of Geomagnetism, Bombay, India
}

(Received November 7, 1996; Revised December 8, 1997; Accepted December 11, 1997)

\begin{abstract}
The Geological Survey of India conducted a magnetic survey and geological studies in 1993 around Barren Island in the Andaman Sea on board the RV Samudra Manthan. Five ocean bottom magnetometers were deployed by the Indian Institute of Geomagnetism as a part of this cruise. The Curie isotherm profiles prepared from the seasurface magnetic data indicate a high heat flow in the east of Barren Island. These profiles also indicate the presence of a north-south structural barrier which has prevented upflow of volcanic material to the west of Barren Island. Ocean-bottom magnetometer data were recorded simultaneously at five sites for about 15 days and these have been used to determine the electrical conductivity structure beneath Barren Island. Magnetic variations recorded at the seafloor stations indicate a concentration of electric currents near the island instead of the usual effect where currents are deflected away from the island. Transfer functions, showing the relationship between the horizontal components of the seafloor stations and land station, have been computed and the quantitative estimates of the transfer functions across Barren Island indicate a high conducting zone at a depth of about $17-27 \mathrm{~km}$. This zone may have been produced by an upwelling of the mantle material through the magma chamber. The structure of this conductive zone at the north and south of Barren Island seems to concentrate the flow of the subsurface electrical currents within the island and the current flow takes a sharp southward turn beneath the island. This north-south conducting zone may have caused a rise in the depth of the Curie isotherm mapped by a shipborne magnetic survey of this region. Most probably, a partial melting of this conductive zone (magma chamber) may have given rise to the volcanic activity on Barren Island.
\end{abstract}

\section{Introduction}

The volcano on Barren Island erupted in 1991 after being quiescent for nearly 200 years. The eruption continued intermittently for months before completely subsiding. The Barren and Narcondum Islands are uninhabited land masses in the Andaman Sea and are a part of the Andaman-Nicobar arc-trench system (Fig. 1). This arc-trench along with the Burmese arc to the north and Sunda arc towards the south, is an important transitional tectonic link between the Himalayan collosion zone to the north and the major island arc trench system of south Asia (Chhibber, 1934). Subduction of Indian plate below the Andaman-Burmese arcs extends to a depth of about 200-220 km (Mukhopadhyay, 1984, 1988; Mukhopadhyay and Krishna, 1991; Dasgupta and Mukhopadhyay, 1993).

The Barren-Narcondam active volcanic arc continues up to the Simenko rift zone (the continental margin arc in Sumatra, Rodolfo, 1969). The volcanism of Sumatra, Borneo and the Andaman Basin was intermittent during Oligocene and Miocene and then became vigorous in Pliocene. Later, it ceased in Borneo but not in the Andaman Basin. The Pliocene tectonism of Andaman is manifested through seis-

*Present address: Ocean Research Institute, University of Tokyo, Japan.

Copy right (C) The Society of Geomagnetism and Earth, Planetary and Space Sciences (SGEPSS); The Seismological Society of Japan; The Volcanological Society of Japan; The Geodetic Society of Japan; The Japanese Society for Planetary Sciences. micity and heat flow characteristics. Results of the International Indian Ocean Expedition data conclusively prove that the Barren and Narcondam Islands, along with the invisible Bank, form the western fringe of the inner volcanic arc. This is also borne out by the results of seismic reflection, magnetic and gravity data in the Andaman Sea (Peter et al., 1966; Curray et al., 1982). These islands are arranged in echelon, more or less subparallel to the axis of the sea floor spreading, and are displaced by a complex system of transcurrent faults.

A magnetic survey can throw useful information on the structure below the island. From the known thermal history of this area, including the recent volcanic eruption, inhomogeneity in the heat flow associated with the volcanism, i.e., magma conduits, etc., are random within the magnetic crust. The magnetic signal up to Curie isotherm will also be random due to a partial or complete loss of magnetism. Thus, a magnetic survey of an east-west profile cutting across the trench system may give vital information on the thermal state of the volcanic system. Since the thermal state of the subsurface structure also strongly influences electrical conductivity, deployment of ocean bottom magnetometers could further supplement the results of the magnetic survey. Thus, the region is a good case for a joint study through magnetic survey and geomagnetic depth sounding (GDS). The joint study has an added advantage in the sense that while the magnetic method would provide information on structure up to Curie depth (a few tens of 


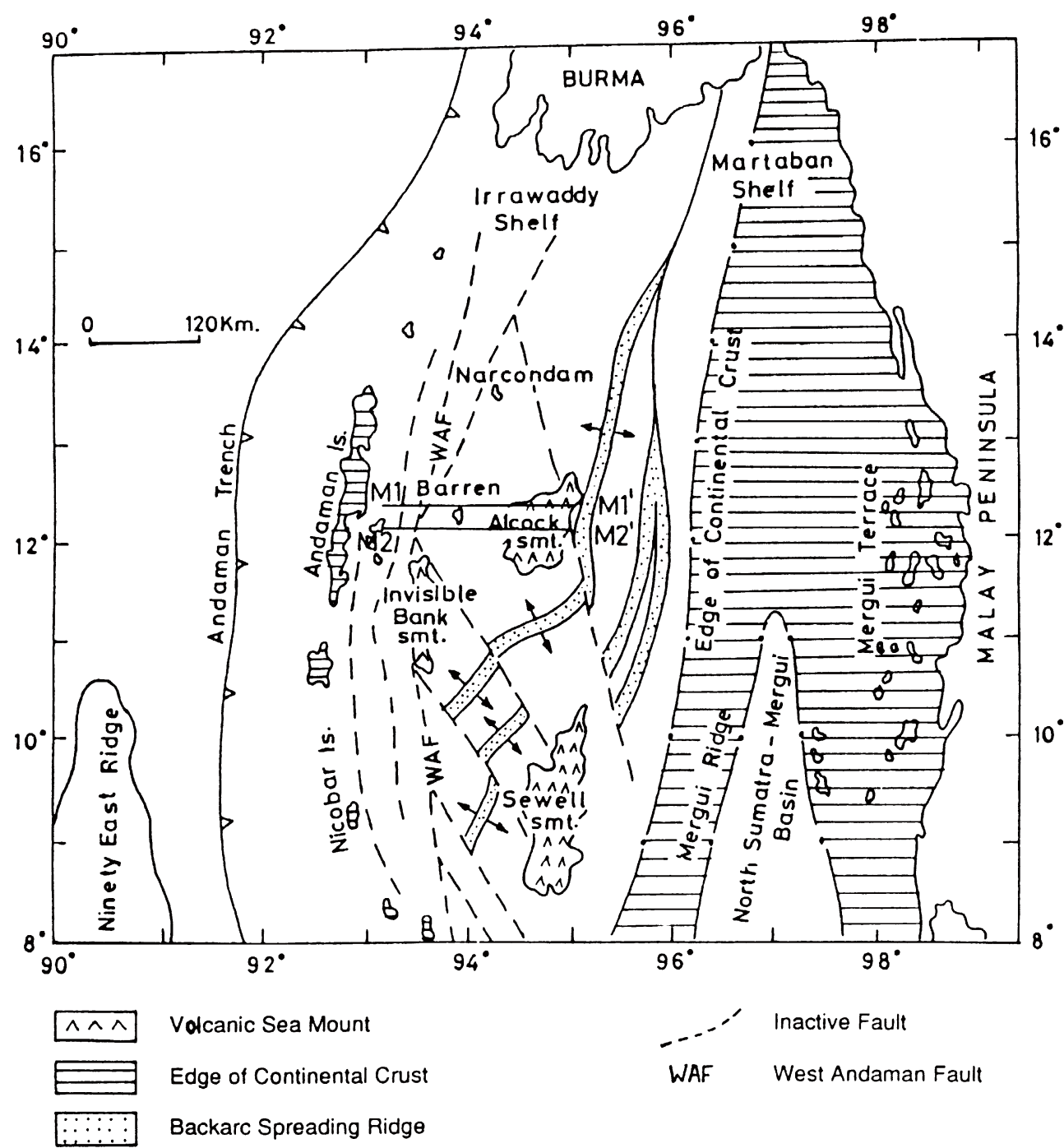

Fig. 1. Tectonic map of the Andaman Sea and surrounding regions (after Curray et al., 1979, 1982). Two magnetic profiles $\mathbf{M}_{1} \mathbf{M}_{1}{ }^{\prime}$ and $\mathbf{M}_{2} \mathbf{M}_{2}{ }^{\prime}$ are shown in this figure.

kilometers), GDS can probe up to a few hundred kilometers. Knowing the thermal state of the shallow layers, we can better understand the electrical conductivity of the deeper layers.

The Geological Survey of India (GSI) conducted a marine magnetic survey in 1993 around Barren Island with a proton precession magnetometer on board the RV Samudra Manthan. A set of five ocean-bottom magnetometers were deployed for geomagnetic depth sounding studies using the set available from the Indian Institute of Geomagnetism, Bombay. Some geological studies were simultaneously conducted. Results from magnetic survey and geomagnetic depth sounding are given in the following sections.

\section{Magnetic Survey}

Total magnetic field measurements were made along two profiles at $12^{\circ} 15^{\prime} \mathrm{N}$ and $12^{\circ} 18^{\prime} \mathrm{N}$ latitudes extending from $93^{\circ} 10^{\prime} \mathrm{E}$ to $95^{\circ} \mathrm{E}$ longitude. The two profiles are just north and south of Barren Island $\left(12^{\circ} 16.5^{\prime} \mathrm{N}, 93^{\circ} 52^{\prime} \mathrm{E}\right)$. The IGRF 1990.0 reduced magnetic anomaly profiles are shown in Fig. 2 along with bathymetry.

A comparison of the two profiles reveals that the bathym- etry is almost parallel. Geological samples show that the area has little or no sediments. The sea bed physiography could thus be taken to represent the basement topography. The close parallelism of the bathymetry along the two profiles suggests that the basement around Barren Island is two-dimensional. Deviations from the two-dimensionality of the subbasement features are bound to be reflected in the morphology of the basement. Incidentally, our point of interest in the subbasement is up to the bottom of the magnetic crust, i.e., the depth up to which static magnetic signals are generated.

Presuming that the subbasement feature is two-dimensional in this area, the magnetic signals recorded along the two profiles separated by $5 \mathrm{~km}$, should be quite correlatable, while a comparison of the magnetic profiles shows no correlation from $95^{\circ} \mathrm{E}$ to nearly $93^{\circ} 45^{\prime} \mathrm{E}$. Magnetic heterogeneity in the subbasement feature east of Barren Island is difficult to visualise from the geological point of view. Nonetheless, a reason for the inhomogeneity of the magnetisation is not hard to find from the known thermal history of this area, including the recent volcanic eruption. The heat flow associated with the volcanism, i.e., magma 


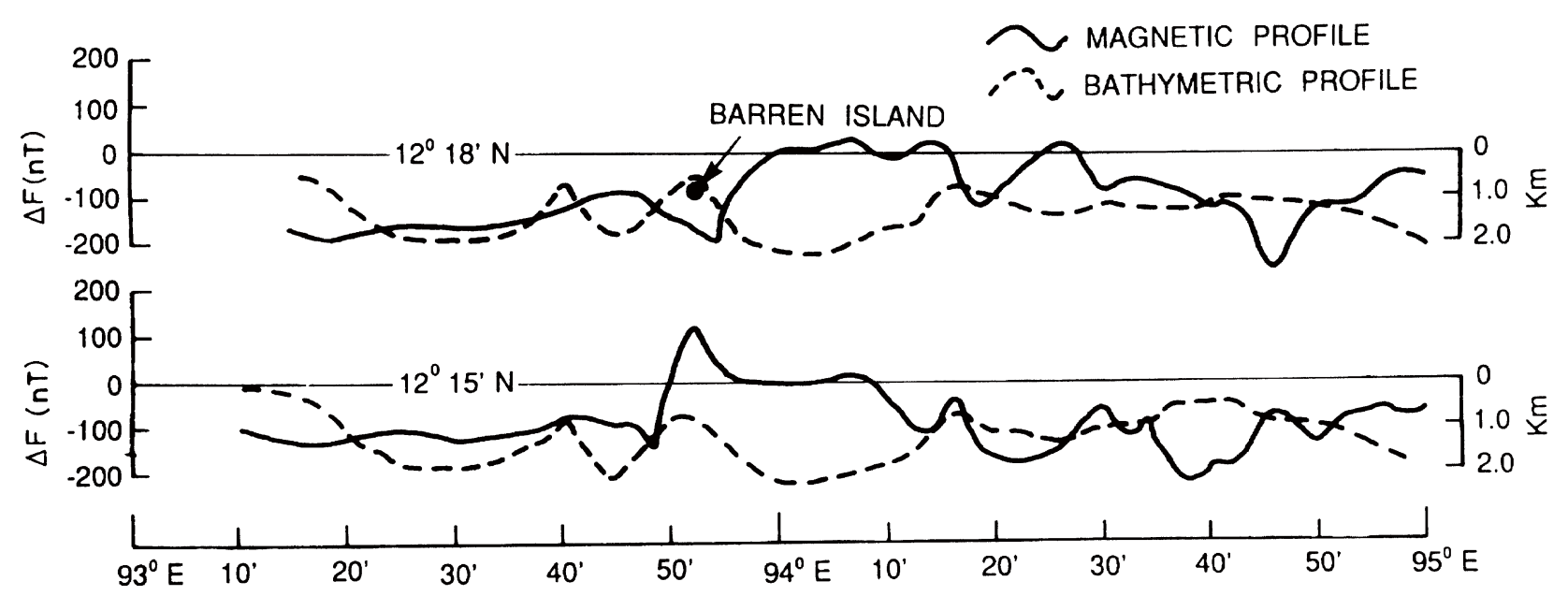

Fig. 2. Magnetic profiles along $\mathrm{M}_{1} \mathrm{M}_{1}{ }^{\prime}$ and $\mathrm{M}_{2} \mathrm{M}_{2}{ }^{\prime}$ across Barren Island (along with bathymetery) are shown in this figure.

(a)

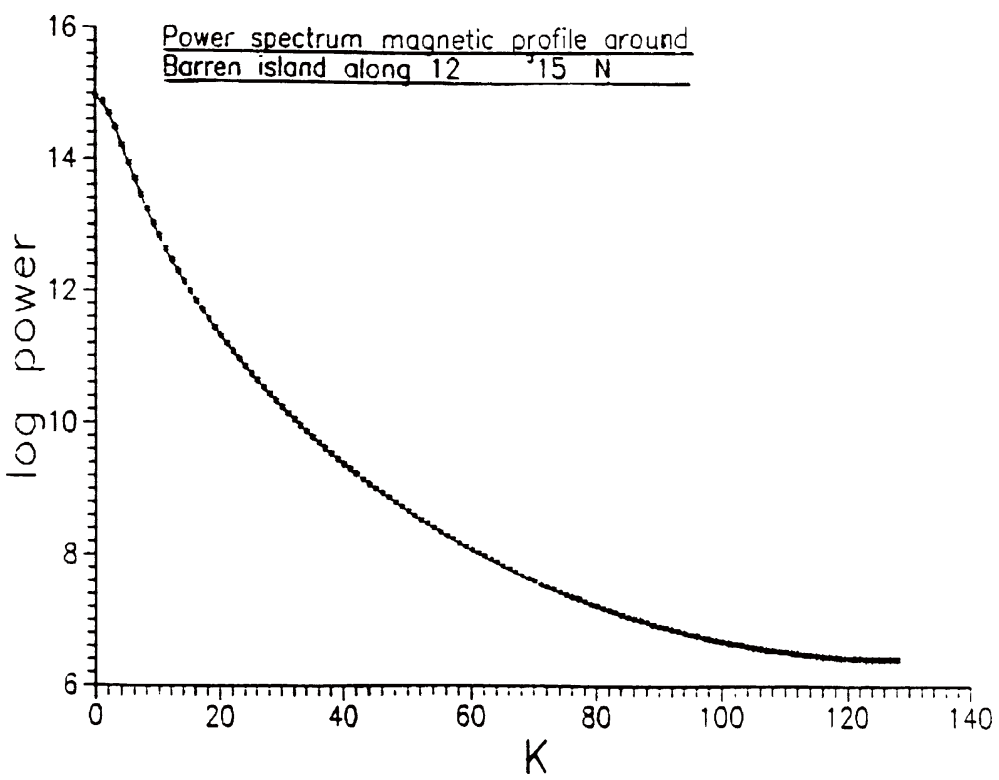

(b)

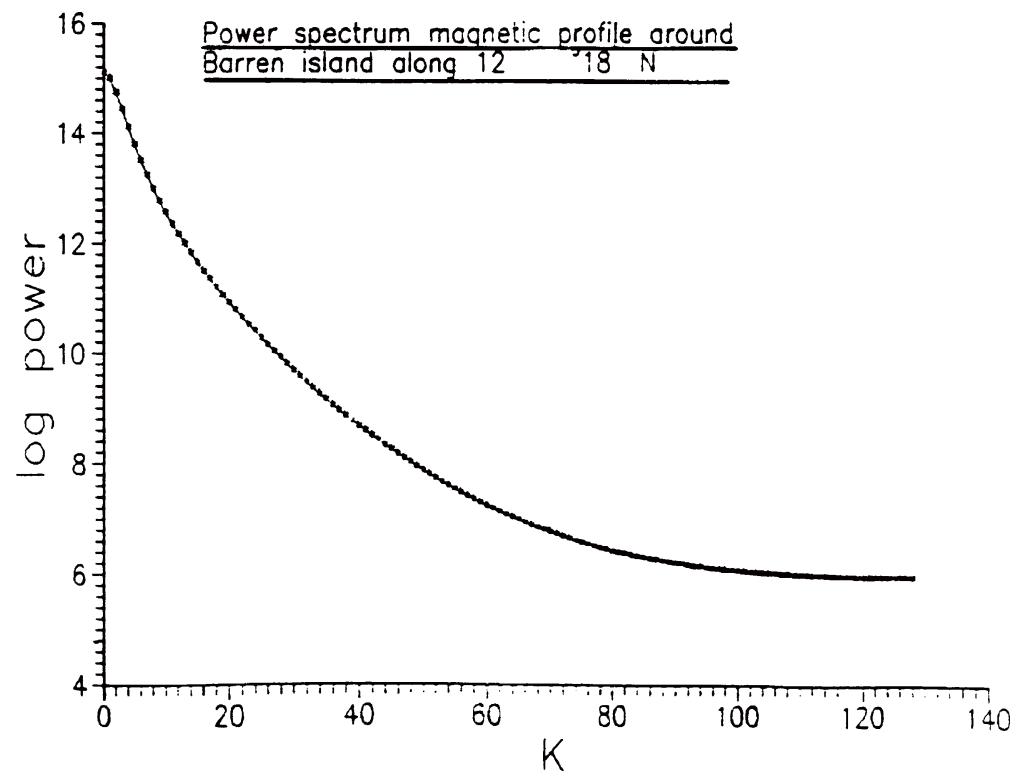

Fig. 3. Power spectrum of two magnetic profiles along $\mathrm{M}_{1} \mathrm{M}_{1}{ }^{\prime}$ and $\mathrm{M}_{2} \mathrm{M}_{2}{ }^{\prime}$ obtained by the conventional method. 
conduits, is randomly distributed within the magnetic crust; the magnetic signal up to Curie depth will also be random due to a partial or complete loss of magnetism.

In the absence of heat flow data, the two magnetic profiles (Fig. 2) could be used to compute the depth to the Curie isotherm. The depth to the deepest interface was calculated both from the conventional power spectrum (Treitel et al., 1971; Pederson, 1991) and from maximum likelihood methods (Fisher, 1958; Davies, 1982). The latter is more useful because of its limited subjectivity. The length of each profile being $200 \mathrm{~km}$, any magnetic interface up to $25-30 \mathrm{~km}$ is supposed to be reflected in the power spectrum (Cianciara and Mareek, 1979). The power spectrum plots obtained from the conventional method are shown in Figs. 3(a) and 3 (b) and from the maximum likelihood method are shown in Figs. 4(a) and 4(b). From both Figs. 3 and 4, the depth to the deepest magnetic interface (i.e., Curies isotherm) is about 3-4 km. Since the average Curie isotherm surface in the sea (nongeothermal area) is less than $20 \mathrm{~km}$ (Condie, 1982) and Barren Island is a known geothermal zone, a Curie isotherm depth of 3-4 km from the above magnetic profiles is not unreasonable. As the depth to the Curie isotherm is small, we have broken each profile into eight short profiles of approximately $75 \mathrm{~km}$ length with $75 \%$ overlapping and calculated the average Curie depth of each short profile. Such a division has been done to see the variation of depth of the Curie isotherm along the profile. The maximum likelihood method is more useful for this situation as it gives a better resolution of the spectrum for shorter data lengths. The plot of the Curie depths for two profiles along latitudes $12^{\circ} 15^{\prime} \mathrm{N}$ and $12^{\circ} 18^{\prime} \mathrm{N}$ are shown in Fig. 5 .

A comparative study of the Curie isotherm depths along

(a)

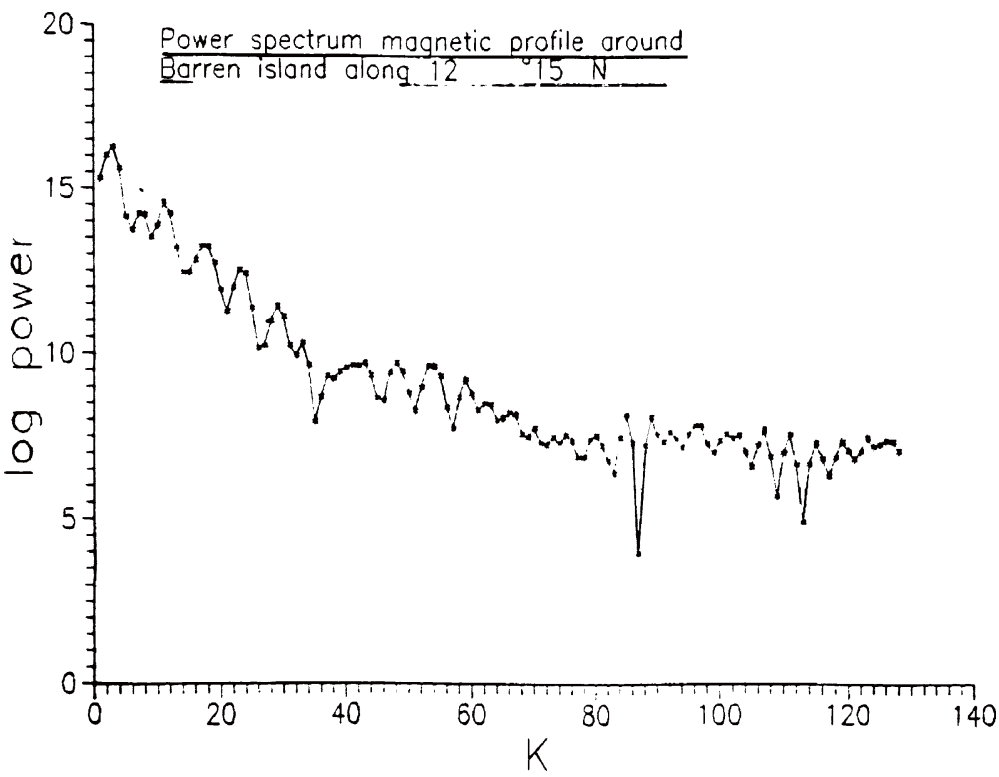

(b)

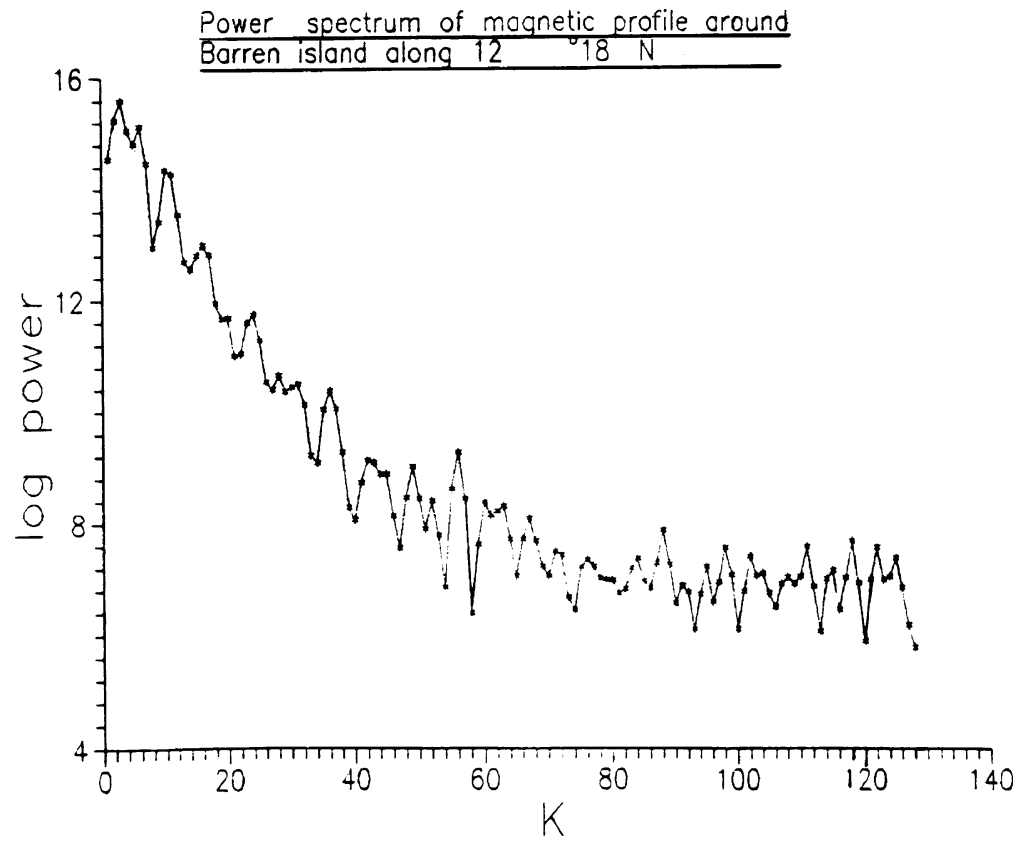

Fig. 4. Power spectrum of two magnetic profiles along $\mathrm{M}_{1} \mathrm{M}_{1}{ }^{\prime}$ and $\mathrm{M}_{2} \mathrm{M}_{2}{ }^{\prime}$ obtained by the maximum likehood method. 


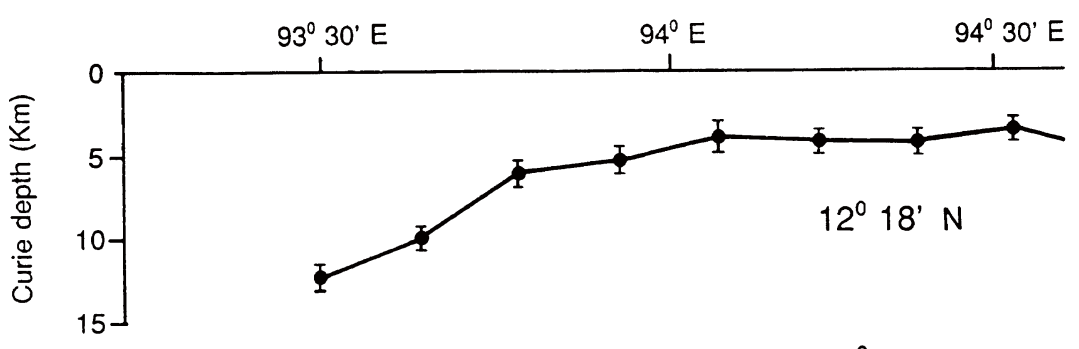

Barren Island $12^{\circ} 16^{\prime} \mathrm{N}$

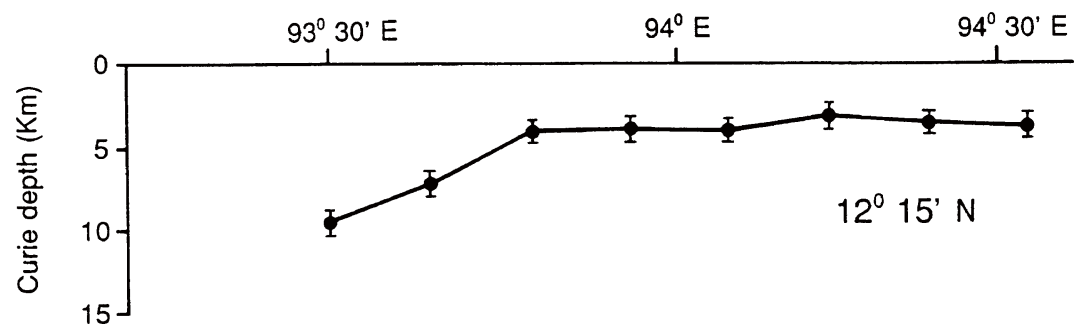

Fig. 5. Curie isotherm depth obtained from the power spectrum along two magnetic profiles across Barren Island.

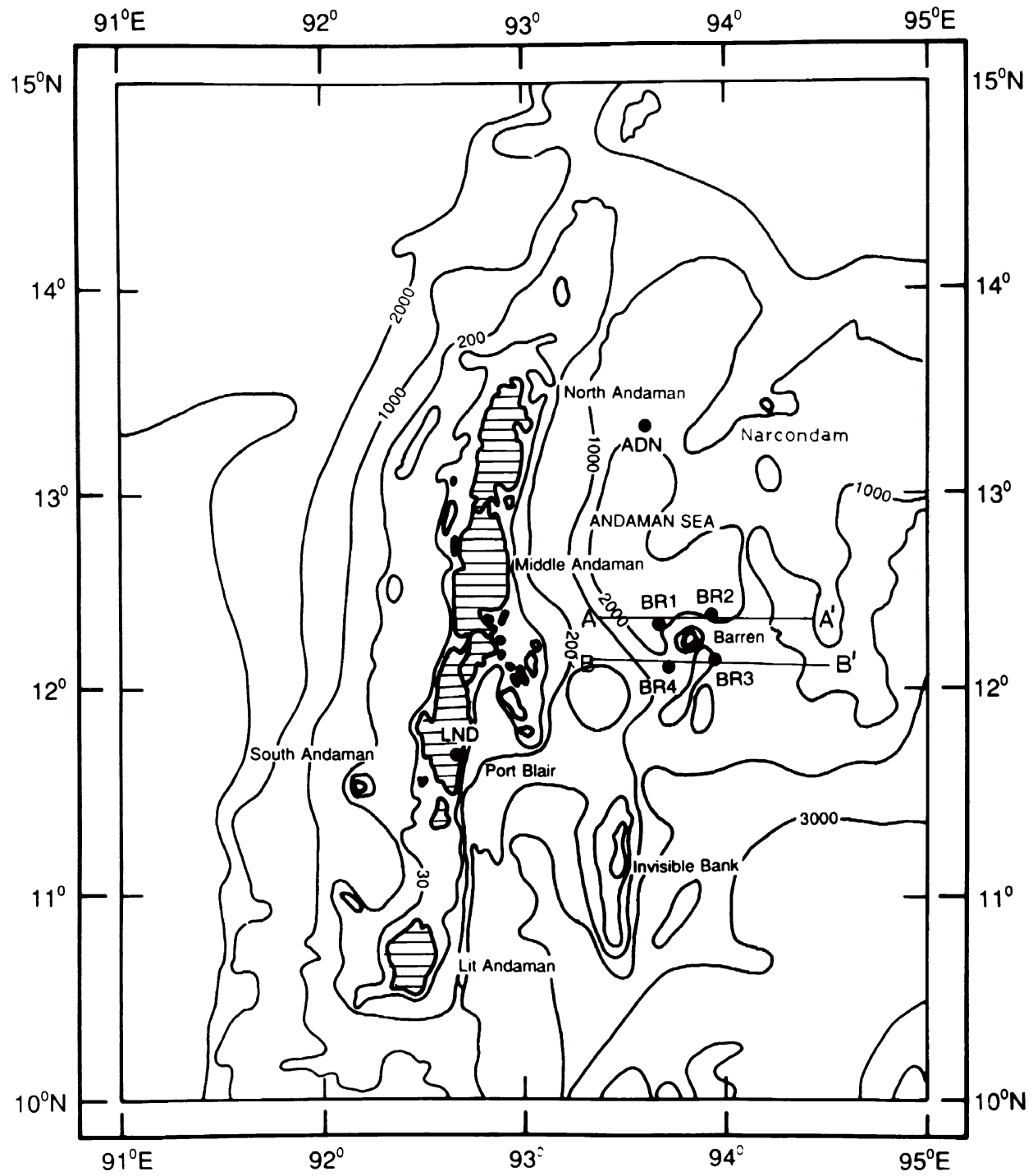

Fig. 6. Bathymetery of the Andaman Sea and surrounding regions showing the location of ocean-bottom magnetometers near Barren Island (BR , $_{\text {B }}$, $\mathrm{BR}_{3}$ and $\mathrm{BR}_{4}$ ). The land station located at Port Blair (LND) is also shown in the figure. The hatched portion indicates Andaman and Nicobar Islands. 
$12^{\circ} 16^{\prime} \mathrm{N}$ and $12^{\circ} 18^{\prime} \mathrm{N}$ reveals that although there is a qualitative agreement between the two in the east of Barren Island, quantitative variations are not small enough to be ignored. The quantitative change in the Curie depth may denote that the heat flow was nonuniform which possibly indicates that the magma conduits were randomly distributed.

A question naturally arises as to why the heat flow was prevented from reaching the surface west of Barren Island? The possible explanation is that there must be some "structural barrier" aligned north-south which acted as a barrier for heat flow or magma conduits. The volcanism has thus been manifested in several cracks and fissures only in the eastern sector before finally erupting in Barren Island. Though it has not been reported earlier, we conclude that the eastern and western parts of the Barren Island belong to two different tectonic regimes separated by a deep seated tectonic barrier.

\section{Geomagnetic Depth Sounding}

The technique of geomagnetic depth sounding (GDS) involves deployment of an array of magnetometers, recording variations in the three components of the magnetic field and determining therefrom the electrical conductivity of the subsurface structure. Recently, ocean-bottom magnetometer array studies were carried out across the Ryukyu Trench-Arc system by Shimakawa and Honkura (1991). Both magnetotelluric and magnetovariational studies have been carried out across the Juan de Fuca plate and the adjacent continent (NW United States) by the EMSLAB group (1988). Previous seafloor measurements have been made in the ocean basins (Phoels and Von Herzen, 1976; Filloux, 1977; Cox et al., 1980), across the Mid-Atlantic ridge at Iceland (Hermance and Garland, 1968; Beblo and Bjornsson, 1978), across the Japan trench in the NW Pacific Ocean (Yukutake et al., 1983) and in the Tasman Sea (Lilley (a)

$x$
$110 n T$

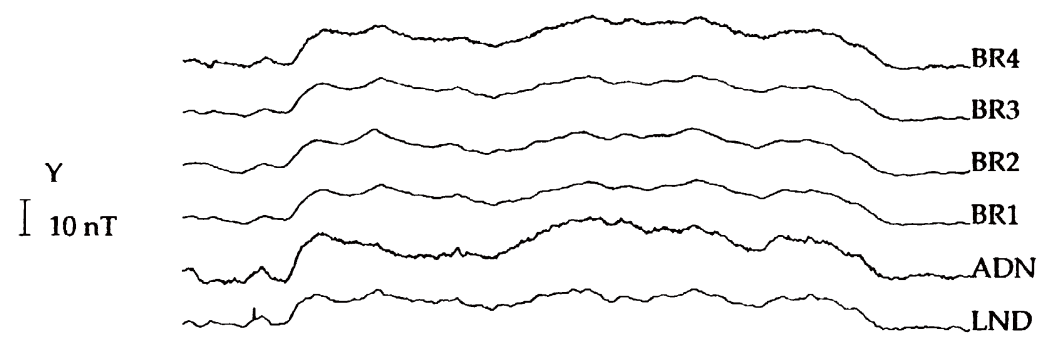

Z

I $10 \mathrm{nT}$

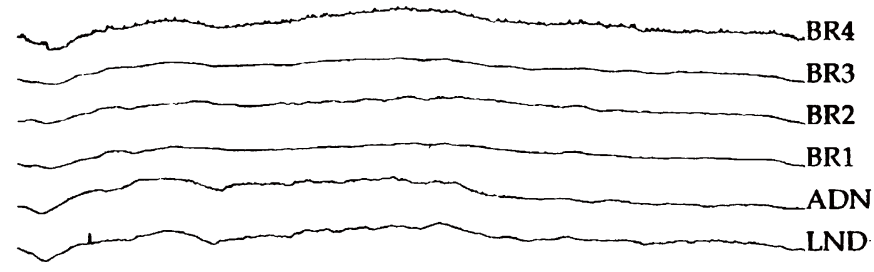

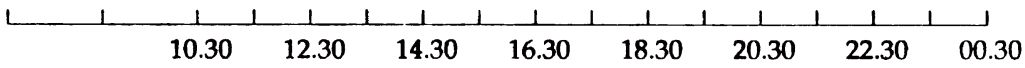

Fig. 7. (a) Magnetograms for the nighttime variations (10.30-00.30 UT) recorded at the $O B M$ stations $\mathrm{ADN}, \mathrm{BR}_{1}, \mathrm{BR}_{2}, \mathrm{BR}_{3}$ and $\mathrm{BR}_{4}$ and at the land station (LND) on 20-21 February 1993 are shown in the figure. It is interesting to note that the amplitude of $X$ and $Y$ variations recorded at the OBM stations are larger, as compared to the LND station. (b) Same as (a). But for events recorded on 22-23 February 1993 are shown in this figure. 
et al., 1989; Ferguson et al., 1990) and high electrical conductivity layers have been found in the asthenosphere.

The magnetotelluric method has been adopted to the study of the suboceanic conductive structure (Filloux, 1967; Cox et al., 1970; Schmucker, 1970). The electromagnetic impedance on the seafloor can be determined by measuring the orthogonal magnetic and electric horizontal field components on the ocean floor or by measuring the attenuation of a horizontal magnetic field component $B_{x}$ between the seasurface $\left(B_{x}^{-}\right)$and the seafloor $\left(B_{x}^{+}\right)$to determine the coefficient of attenuation $R(\omega)$,

$$
R(\omega)=\frac{B_{x}^{+}(\omega)}{B_{x}^{-}(\omega)}
$$

In the present case, we have used this technique and, since it is difficult to measure magnetic variations on the seasurface, measurements made at nearby land stations are taken to be equivalent to the measurements made at the seasurface.

\subsection{Data collection and processing}

Four ocean-bottom magnetometers (OBM's) were lowered around Barren Island as shown in Fig. 6. One more was placed in the Andaman Sea (marked as ADN) far away from Barren Island to act as a reference station. The position of the OBM's are marked in the figure. Simultaneously, data were also collected from a land station (shown as LND in the figure) which is located at Port Blair. These instruments collected data for about 15 days during February-March 1993. The deployment and retrieval of the OBM's were carried out abroad the RV Samudra Manthan.

The construction of the OBM's is given in Segawa et al. (1986). The instrument collected data at a 1 min sampling rate and stored variations in three components at $1 \mathrm{~min}$ intervals. The accuracy of the sampled value is quite high $(<1 \mathrm{nT})$. The data were stored in a programmable read only memory (PROM) card. The OBM is dropped into the sea and left to settle at the ocean bottom. It goes down because of the heavy lead mass attached to it and buoys up when the lead mass is detached. It settles at the sea bottom in a random

(b)

I $10 \mathrm{nT}$

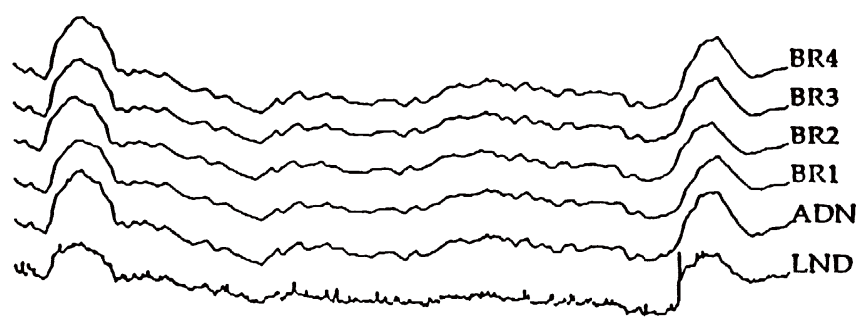

Y

I $10 \mathrm{nT}$

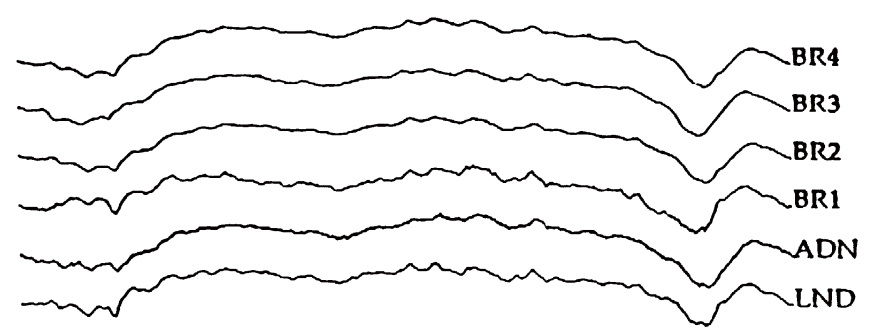

Z

I $10 \mathrm{nT}$

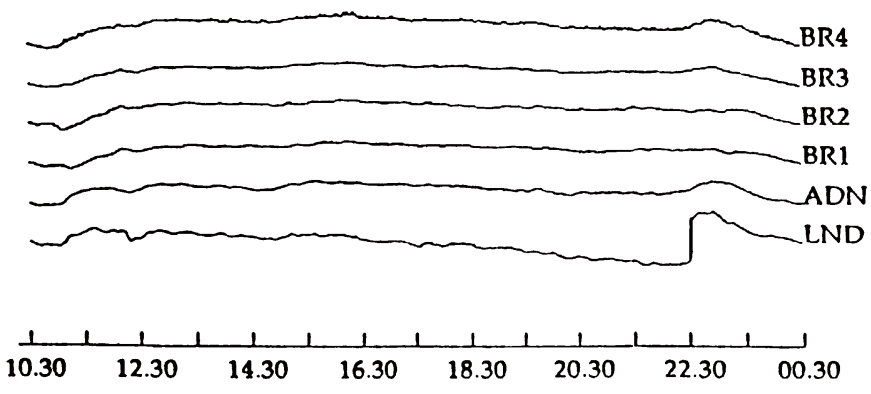

Fig. 7. (continued). 
orientation. Being loaded with a heavy weight, it always settles upright. The sensors' assembly is mounted on a gimbal whereby the $X, Y$ sensors are in the horizontal plane, while the $Z$ sensor is oriented in the vertical plane. Thus, the $Z$ sensor measures the $Z$ component directly, while the two horizontal sensors are in an unknown orientation. However, the data recorded by the two horizontal sensors are in a direction orthogonal to each other but at a random orientation with respect to geographical north and east. Their orientation with respect to geographical north and east can be estimated by using model values from the IGRF (International Geomagnetic Reference Field). Once the orientation of the horizontal sensors becomes known, the recorded $X$ and $Y$ variation can be transferred to $X, Y$ variations in geographical north and east directions.

\subsection{Magnetograms}

A few events from various records were selected to provide moderate magnetic disturbances with a variety of polarizations. Stacked plots of events recorded on 20-21 and 22-23 February 1993 during 10.30-00.30 UT are shown in Figs. 7(a) and 7(b). Since the area of study is in an equatorial region, we use nighttime events to ensure that the inducing field is uniform and the $Z$ component has no external origin. The $Z$ variation is consistently weak at all stations near Barren Island, i.e., $\mathrm{BR}_{1}, \mathrm{BR}_{2}, \mathrm{BR}_{3}$ and $\mathrm{BR}_{4}$. The nearly zero $Z$ variations recorded near Barren Island thus give no evidence of lateral conductivity contrast underneath. However, $Y$ variations recorded at all four OBM stations indicate a current concentration beneath Barren Island. As external currents do not have $Y$ components near the equator, the observed $Y$ variations are due to internal origin. The recorded $Y$ variations are opposite in phase to the $X$ variations. It is interesting to note that the amplitude of $X$ and $Y$ variations are very large at $\mathrm{BR}_{1}, \mathrm{BR}_{2}, \mathrm{BR}_{3}$ and $\mathrm{BR}_{4}$ when compared to the land station (LND). The low $X$ and $Y$ variations observed at the LND station may be due to the island effect which is caused by the perturbation of electric current induced in the sea surrounding the island. Thus, seawater acts as a low pass filter in transmitting the electromagnetic waves (Heinson and Lilley, 1989). If the island effect is removed, then one can estimate the attenuation of the horizontal magnetic field components between the reference and seafloor stations. This effect has been estimated by using thin-sheet approximation and is described later.

\subsection{Transfer functions for the horizontal components}

Transfer functions showing the relationship between seafloor horizontal components $\left(X_{\mathrm{sf}}\right.$ and $\left.Y_{\mathrm{sf}}\right)$ and land station horizontal components $\left(X_{1}\right.$ and $\left.Y_{1}\right)$ are estimated from the magnetic storm/bay by using tensor analysis (Cochrane and Hyndman, 1970). Analysis has been carried out in the frequency domain. The relationship between the horizontal field components and transfer functions are given by

$$
\begin{aligned}
& X_{\mathrm{sf}}=A X_{1}+B Y_{1}, \\
& Y_{\mathrm{sf}}=C X_{1}+D Y_{1},
\end{aligned}
$$

where $A, B$ and $C, D$ are transfer functions for the north and east components of geomagnetic field variations between land and various seafloor stations.
The following assumptions have been made to estimate the above transfer functions:

(1) In the present case, magnetic field variations at Port Blair station (LND) have been extrapolated to estimate the variations at the sea surface above the seafloor stations. Since, we are considering nighttime variations, the source field is uniform over the area of study and there is no locally induced variations.

(2) There are no magnetic fields induced by water motion within the ocean and the reference station is free from anomalous magnetic field variations.

(3) The horizontal field gradients are much smaller than the vertical field gradients.

Three events recorded on 20, 21 and 22 March 1993 are considered for estimating the transfer functions. Since the observations are made near the equatorial region, only nighttime variations are considered for estimating the transfer functions, as otherwise nonuniformity in the source field would crop up due to daytime equatorial electrojet. The transfer functions A and D have been rotated in the direction of the maximum diagonal elements such that they show attenuation of the horizontal geomagnetic field components on the seafloor by the induced currents in the ocean when land reference station is located at the sea surface just above the seafloor station (Shimakawa and Honkura, 1991). The electrical conductivity structure beneath the seafloor depends upon the horizontal geomagnetic field components at the seafloor station. They are strongly attenuated if the structure below the seafloor is resistive and enhanced if it is conductive. These transfer functions (A and D) have been used in this study.

The transfer functions have been estimated for stations $\mathrm{BR}_{1}, \mathrm{BR}_{2}, \mathrm{BR}_{3}, \mathrm{BR}_{4}$ and $\mathrm{ADN}$. The transfer functions for station $\mathrm{BR}_{3}$ are shown in Fig. 8. As seen from the figure, the magnitude of transfer functions $A$ and $D$ is significant as compared to B and C. Both transfer functions A and D decrease montonally with frequency. This behaviour is also observed at other stations. Thus, as seen from Eqs. (2) and (3), most of the $X_{\text {sf }}$ is correlated with $X_{1}$ and similarly, $Y_{\text {sf }}$ with $Y_{1}$. Moreover, the magnitude of $\mathrm{D}$ is much larger than A. As external currents do not produce any $Y$-components near the equator, the observed $\mathrm{D}$ variations are due to the internal origin. Thus, the above observations indicate that the conductivity structure is mostly of a $2 \mathrm{D}$ nature and extending in an eastwest direction. It has been mapped in 2D modelling and is discussed in Subsection 3.5.

\subsection{Thin-sheet modelling for the island effect}

The coastline of the Andaman and Nicobar islands (Fig. 9) is so complex that it cannot be approximated to a $2 \mathrm{D}$ structure. Numerical solutions of 3D structures are very limited in the literature and a 3D thin sheet of variable conductance is considered to estimate the island effect at the LND station.

If the conductivity anomalies are confined to a surficial layer, the computational procedure can be greatly simplified by replacing the nonuniform layer as a thin sheet of variable conductances (Price, 1949). It was further pointed out that charges collected at conductivity discontinuities are bound to effect the local electrical field (Price, 1973). Two formulations approximating 3D structures in thin-sheet ap- 

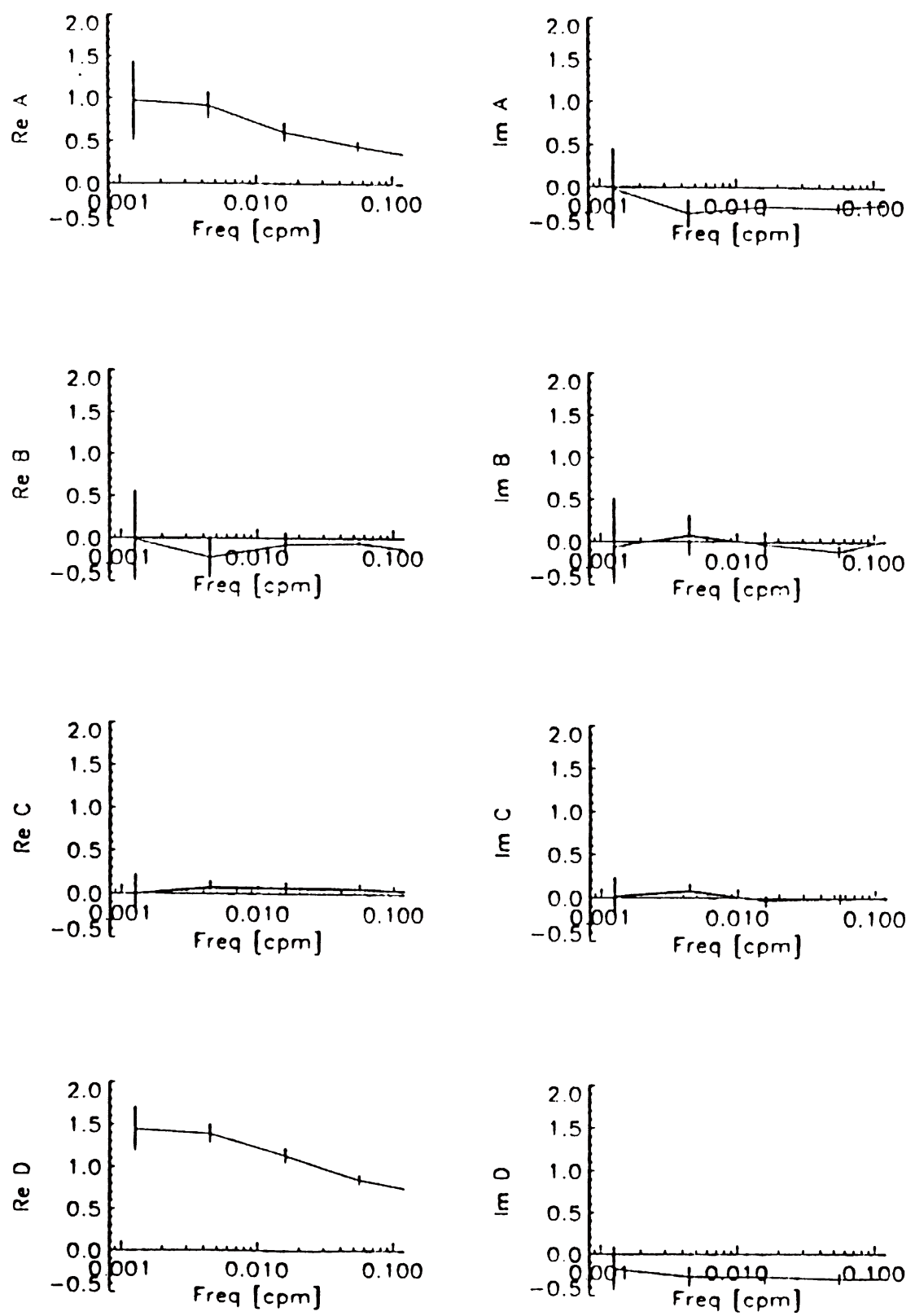

Fig. 8. Horizontal transfer functions for the northern (A and B) and eastern (C and D) components of geomagnetic variations between the land reference station (LND) and the seafloor station $\mathrm{BR}_{3}$. It is interesting that the amplitudes of $\mathrm{D}$ variations are greater than $\mathrm{A}$. Error bars denote the $95 \%$ confidence intervals of respective estimates.

proximation for regional studies have been developed independently by Vasseur and Weidelt (1977) and by Dawson and Weaver (1979). Both this algorithms have been applied to a variety of synthetic problems. We have used the program of Vasseur and Weidelt for estimating the island effect for the LND (Port Blair) station because it allows an evaluation of the response for much longer periods than Dawson and Weaver's formulation.

In Vassuer and Weidelt's algorithm, the anomalous domain (region considered for modelling) should be surrounded by a region of normal structure. Since the anomalous domain is surrounded by a region of normal structure, the unrealistic grid boundary effects are minimised by extending the grid to sufficiently larger distances away from the observational domain. The rectangular block shown in Fig. 9 is the region considered for thin-sheet modelling. For computational purpose, the Andaman and Nicobar islands and surrounding sea is divided into grids of 10 by 24 meshes, with a grid spacing of $20 \mathrm{~km}$. The thin sheet of variable conductance and a thickness of $6 \mathrm{~km}$ is considered to overlie a halfspace of 1000 Ohm-m resistivity (Weaver, 1982; Jozwick and Beamish, 1986). Each cell in the anomalous region is coded to denote its conductance. Thus, the code 1 signifies the continental crust of conductivity $0.05 \mathrm{~S} / \mathrm{m}$. Its conductance is $6000 \times 0.05=30 \mathrm{~S}$. Similarly, the code 4 signifies seawater $(3.3 \mathrm{~S} / \mathrm{m})$ of $1 \mathrm{~km}$ thickness and $5 \mathrm{~km}$ thick sediments $(0.1$ $\mathrm{S} / \mathrm{m})$. Its conductance is $1000 \times 3.3+5000 \times 0.1=3800 \mathrm{~S}$. Other conductance values are shown in Fig. 9. The normal structure outside the anomalous domain is represented by a medium of $3800 \mathrm{~S}$, equivalent to the conductance of cell No. 4 .

The above thin sheet should satisfy certain physical conditions for a given period, i.e., the thickness of the thin 
Table 1. Estimated transfer functions at the LND (Port Blair) station after eliminating the island effect. Transfer functions shown in bracket are (Real, Imaginary).

\begin{tabular}{rlllc}
\hline Period & \multicolumn{1}{c}{ A } & \multicolumn{1}{c}{ B } & C & D \\
\hline 256 & $(0.794,-0.698)$ & $(-0.01,-0.004)$ & $(0.010,0.003)$ & $(0.736,-0.096)$ \\
118 & $(0.756,-0.569)$ & $(0.011,0.004)$ & $(0.051,0.020)$ & $(0.686,-0.086)$ \\
55 & $(0.728,-0.034)$ & $(0.013,0.005)$ & $(0.009,0.004)$ & $(0.644,-0.069)$ \\
25 & $(0.725,-0.004)$ & $(0.016,0.007)$ & $(0.012,0.012)$ & $(0.611,-0.049)$ \\
12 & $(0.724,0.027)$ & $(0.020,0.008)$ & $(0.015,0.015)$ & $(0.594,-0.026)$ \\
\hline
\end{tabular}

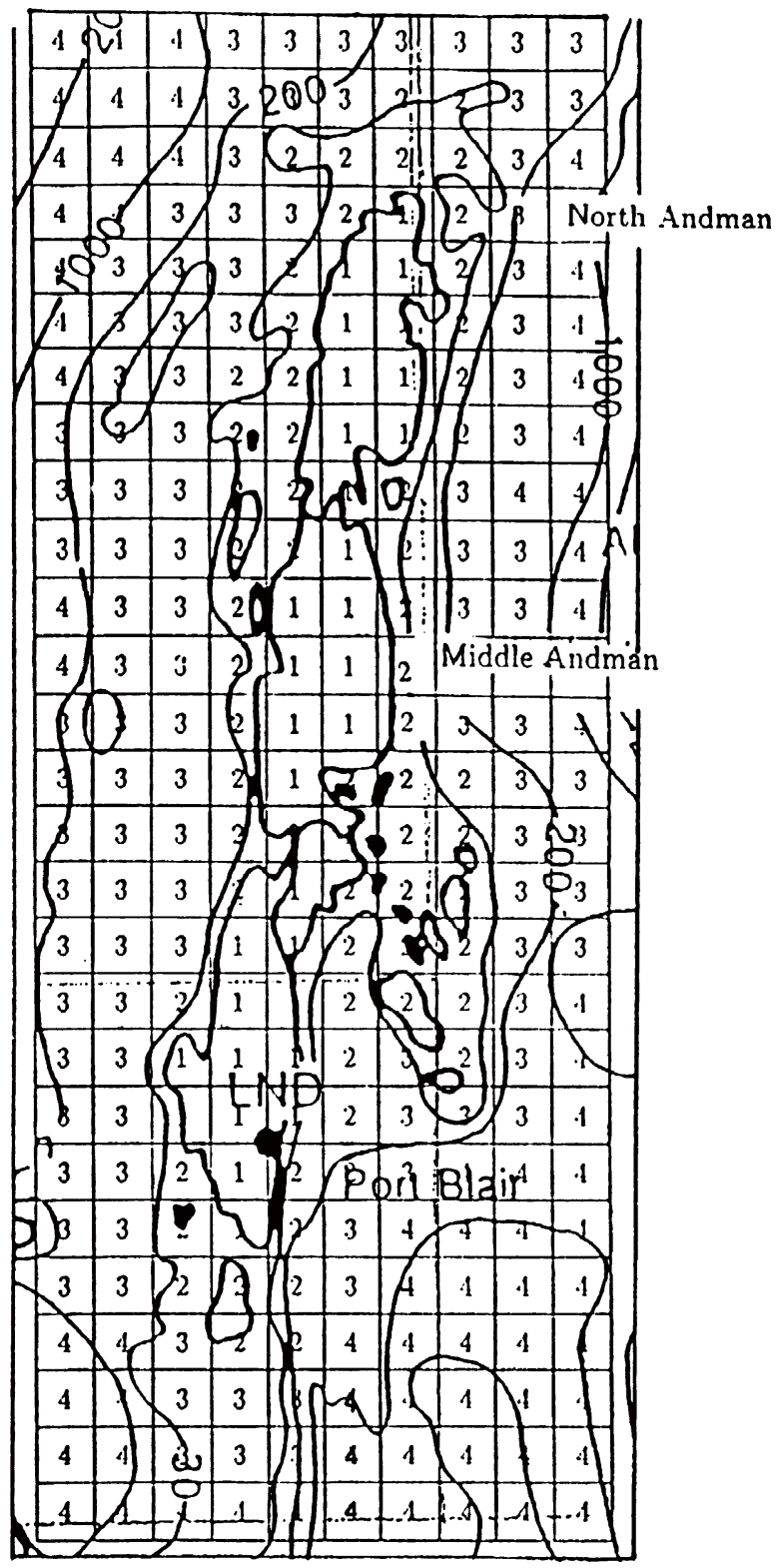

\begin{tabular}{cc}
\hline No. & Conductance (S) \\
1 & 30 \\
2 & 449 \\
3 & 1065 \\
4 & 3800
\end{tabular}

Fig. 9. Conductance map of the Andaman and Nicobar islands and surrounding region. The amplitude of $X$ and $Y$ variations at the land reference station (LND) has been reduced by $20 \%$ due to the surrounding sea. sheet must be less than the skin depth of the underlying substratum and should be small compared to the skin depth in the material forming the thin sheet itself (Agarwal and Weaver, 1989). These conditions ensure that all the materials in the thin sheet itself are electrically linked to the substratum, so that at the period of interest, the horizontal electric field remains constant over the thickness of the sheet (Weaver, 1982). In the present case, the skindepth of the underlying layer for $26 \mathrm{~min}$ is about $652 \mathrm{~km}$ and is much larger than the assumed thickness $(6 \mathrm{~km})$ of the anomalous surface layer. Similarly, the skin depth of the seawater is approximately $10 \mathrm{~km}$, again about 10 times larger than the maximum depth of the seawater. Thus, the thin sheet conditions are satisfied everywhere. Computations have been carried out for 12, 26, 55, 119 and 256 min periods. From the above calculations, it has been observed that the amplitude of $X$ and $Y$ variations at the land reference station (LND) have been reduced by $20 \%$ due to the island effect. The transfer functions obtained after eliminating the island effect at the LND station are shown in Table 1. The above transfer functions obtained after eliminating the island effect at the LND station have been considered while interpreting the transfer functions in terms of 2D models.

\subsection{Two-dimensional modelling}

As seen from Fig. 8, the amplitude of transfer functions A and $\mathrm{D}$ are different and deviate from a $1 \mathrm{D}$ structure. These may be due to the $X$ and $Y$ variations having a different lateral conductivity contrast. Most probably, a better explanation can be found with the source fields. Therefore, apparent resistivities and phases calculated from A transfer functions by using Schmucker's technique (Schmucker, 1970; Section 5) being used as a normal structure. This structure across four Barren Island stations indicates that the total thickness of the oceanic crust and upper mantle is about $80 \mathrm{~km}$ with a resistivity of about $30 \mathrm{Ohm}-\mathrm{m}$ and is underlain by a layer of 16 Ohm-m.

The observed transfer functions (D) have been interpreted by using a 2D program (Schmucker, 1971, 1995) which is based on the integral equation approach. In this algorithm, the anomalous domain must be surrounded by a normal structure. The normal structure is described above and has been used for modelling. Two profiles $\mathrm{AA}^{\prime}$ (across $\mathrm{BR}_{1}$ and $\mathrm{BR}_{2}$ ) and $\mathrm{BB}^{\prime}$ (across $\mathrm{BR}_{4}$ and $\mathrm{BR}_{3}$ ) as shown in Fig. 6 have been interpreted in terms of a high conducting layer $(0.25 \mathrm{~S} /$ m) underlying Barren Island at a depth of about 17-27 km. The comparison between calculated and observed transfer functions D is shown in Table 2. At longer periods, both calculated and observed D are comparable within the error 

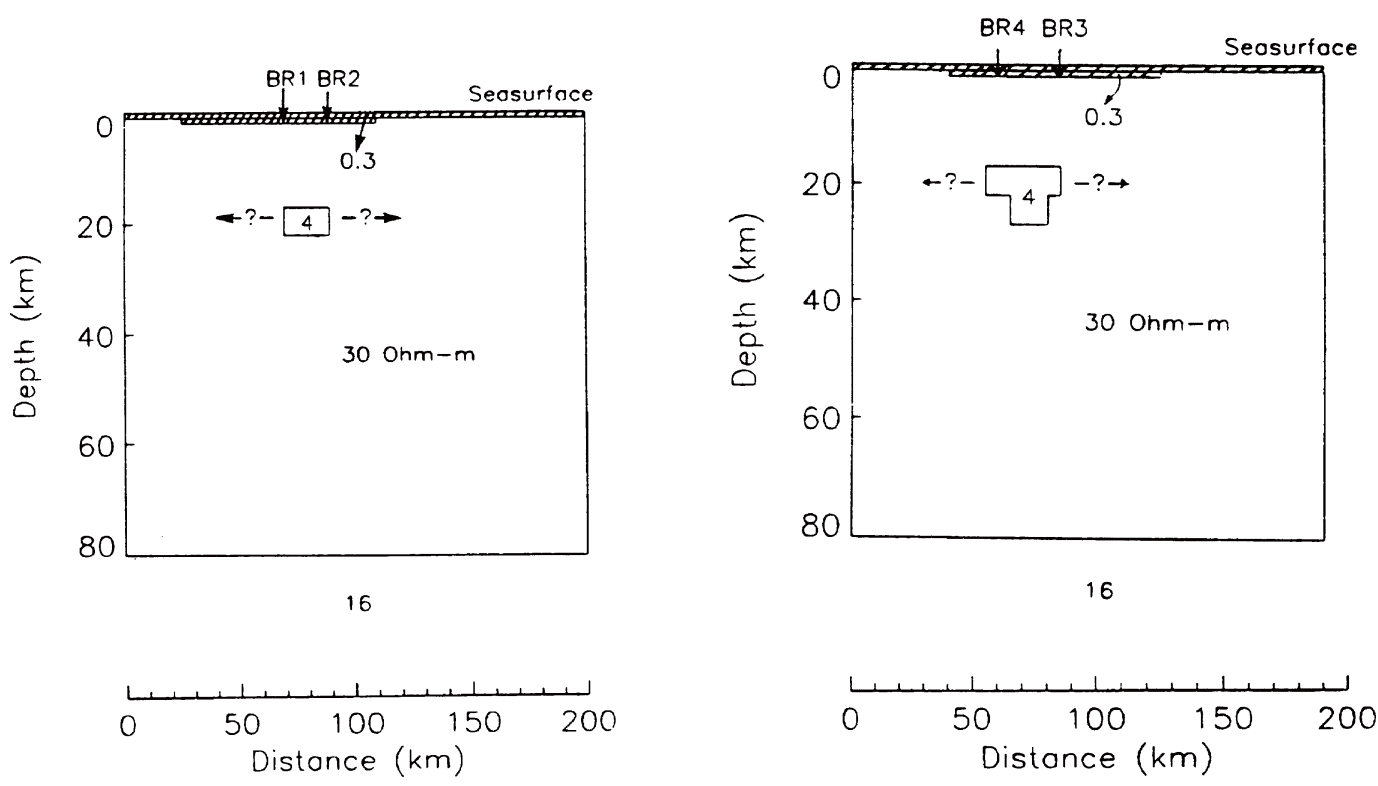

Fig. 10. Geoelectrical structure across profile $\mathrm{AA}^{\prime}$ and $\mathrm{BB}^{\prime}$ obtained by using $2 \mathrm{D}$ modelling. Interpreted models show that a high conducting zone $(0.25$ $\mathrm{S} / \mathrm{m}$ ) is underlying Barren Island at a depth of about $17-27 \mathrm{~km}$.

Table 2. Comparison between calculated and observed transfer functions D.

\begin{tabular}{ccc}
\hline Period & Cal. D & Obs. D \\
\hline STN BR $_{1}$ & & \\
256 & $(0.772,-0.190)$ & $(0.676,-0.704)$ \\
118 & $(0.666,-0.250)$ & $(0.362,-0.703)$ \\
55 & $(0.495,-0.290)$ & $(0.366,-0.181)$ \\
25 & $(0.319,-0.250)$ & $(0.242,-0.176)$ \\
& & \\
STN BR $_{2}$ & & \\
256 & $(0.768,-0.200)$ & $(0.769,-0.626)$ \\
118 & $(0.656,-0.260)$ & $(0.574,-0.580)$ \\
55 & $(0.491,-0.310)$ & $(0.428,0.032)$ \\
25 & $(0.306,-0.280)$ & $(0.254,0.194)$ \\
& & \\
STN BR $_{3}$ & & \\
256 & $(0.767,-0.190)$ & $(0.753,-0.693)$ \\
118 & $(0.653,-0.250)$ & $(0.512,-0.750)$ \\
55 & $(0.496,-0.270)$ & $(0.430,-0.188)$ \\
25 & $(0.333,-0.250)$ & $(0.319,-0.178)$ \\
& & \\
STN BR $_{4}$ & & \\
256 & $(0.776,-0.180)$ & $(0.804,-0.787)$ \\
118 & $(0.666,-0.240)$ & $(0.498,-0.856)$ \\
55 & $(0.515,-0.270)$ & $(0.407,-0.288)$ \\
25 & $(0.358,-0.240)$ & $(0.204,-0.254)$ \\
\hline & &
\end{tabular}

bars. The deviation at shorter periods may be due to the attenuation of geomagnetic variations $(X$ and $Y$ ) below 30 $\min$.

The conductivity of the highly conducting layer obtained by the above method is quite reasonable, as Shankland and Waff (1977), on the basis of laboratory measurements, place the conductivity of magma chamber between 0.01 and $2.0 \mathrm{~S} /$ $\mathrm{m}$. The thickness of the magma chamber is about $5 \mathrm{~km}$ (Fig. 10(a)) across profile $\mathrm{AA}^{\prime}$ north of Barren Island and increases towards the south to about $10 \mathrm{~km}$ (profile BB', Fig. $10(\mathrm{~b})$ ). Due to the concentration of the magma chambers north and south of Barren Island, the currents seem to concentrate within the island and turn towards the south beneath the island. The flow direction of the induced currents in the northern and southern parts of Barren Island indicate that the source for the magma chamber is located to the south of Barren Island.

\section{Conclusions}

Magnetic measurements and ocean-bottom magnetometer surveys have been carried out in Barren Island after a volcanic eruption in 1991. From the spectral analysis of magnetic data, the depth obtained to the Curie isotherm is about 3-5 km on the eastern side of Barren Island, whereas on the western side it falls sharply to $12 \mathrm{~km}$. This indicates a high heat flow on the eastern side of Barren Island associated with volcanism, whereas on the western side, such disturbances have not taken place. Most probably, a structural barrier aligned in the north-south direction has prevented volcanic material flowing towards the west.

The normal structure across Barren Island indicates that it is underlain by a low resistive lithosphere/asthenosphere. This may be due to the hotter crust/lithosphere underlying the Andaman-Burmese arc region. The anomalous transfer functions D have been interpreted in terms of a high conductivity zone $(0.25 \mathrm{~S} / \mathrm{m})$ underlying Barren Island at a shallow depth of $17-27 \mathrm{~km}$. The enhanced conductivity at a shallow depth is due to the concentration of magma chambers that may have been produced by an upwelling of the mantle. The depth of this conducting zone coincides with most of the shallow earthquake events that have taken place in the Andaman arc region (Eguchi et al., 1979; Mukhopadhyay, 1984; Kumar et al., 1996). Most probably, a partial melting of this magma chamber may have given rise to the volcanic activity that took place at Barren Island in 1991 and may have activated the rise in depth of the Curie isotherm mapped by magnetic survey.

The OBM stations chosen for the observations are located 
on the periphery of the shallow conducting layer. A few more OBM stations are needed on either side of Barren Island to get an exact configuration of this anomalous body.

Acknowledgments. The authors are thankful to the Department of Science and Technology and the Department of Ocean Development, Government of India, for providing funds to procure the ocean-bottom magnetometers and to the Marine Wing, Geological Survey of India (GSI) for providing the RV Samudra Manthan. Support given by Mr. B. R. J. Rao and Mr. B. K. Saha and the scientists on board SM 86 is gratefully acknowledged. The scientists from the Indian Institute of Geomagnetism are grateful to Profs. P. Weidelt and U. Schmucker for fruitful suggestions and guidance during this work. One of the authors (B.B.) expresses his appreciation to Prof. B. N. P. Agarwal and Dr. R. K. Shaw for providing software support. He also thanks the Director-General, Geological Survey of India, for his kind permission to publish this paper.

\section{References}

Agarwal, A. K. and J. T. Weaver, Regional electromagnetic induction around the Indian peninsula and Srilanka: a three-dimensional numerical model study using the thin sheet approximation, Phys. Earth Planet. Sci., 54, 310-321, 1989.

Beblo, M. and A. Bjornsson, Magnetotelluric investigation of the lower crust and upper mantle beneath Iceland, J. Geophys., 45, 1-16, 1978

Chhibber, H. L., Geology of Burma, 538 pp., Macmillan \& Co., London, 1934.

Cianciara, B. and H. Mareek, Geophysical anomaly interpretation of potential fields by means of singular point method and filtering, Geophys. Prosp., 27, 251-260, 1979.

Cochrane, N. A. and R. D. Hyndman, A new analysis of geomagnetic depth sounding from western Canada, Can. J. Earth. Sci., 7, 1208-1218, 1970.

Condie, K. C., Plate Tectonics and Crustal Evolution, 3rd ed., 476 pp., Pergamon Press, Oxford, England, 1982.

Cox, C., J. H. Filloux, and J. Larsen, Electromagnetic studies of ocean currents and electrical conductivity below the ocean floor, in The Sea, 4, pp. 637-693, Wiley, New York, 1970.

Cox, C., J. H. Filloux, D. I. Gough, J. Larsen, K. Poehls, R. V. Herzen, and R. Winter, Atlantic lithosphere sounding, J. Geomag. Geoelectr., 32, Suppl., 13-32, 1980.

Curray, J. R., D. G. Moore, L. A. Lawyer, F. J. Emmel, R. W. Raitt, M. Henry, and R. Kieckhefer, Tectonics of the Andaman Sea and Burma in Geological and Geophysical Investigations of Continental Margins, edited by J. S. Watkins et al., AAPG Memoir., 29, 189-198, 1979.

Curray, J. R., F. J. Emmel, D. G. Moore, and R. W. Raitt, Structure, tectonics and geological history of the north eastern Indian Ocean, in The Ocean Basins and Margins, 6, edited by A. E. M. Nairn and F. G. Stehli, pp. 399-450, Plenum Publn., New York, 1982.

Dasgupta, S. and M. Mukhopadhyay, Seismicity and plate deformation below the Andaman arc, northeast Indian ocean, Tectonophysics, 225, 529-542, 1993.

Davies, A. R., On the maximum likelyhood regularization of fredholm convolution equations of the first kind, in Treatment of Integral Equations by Numerical Methods, edited by C. T. Baker and G. F. Miller, pp. 95-105, Academic Press, New York, 1982.

Dawson, T. W. and J. T. Weaver, Three dimensional induction in a nonuniform thin sheet at the surface of a uniformally conducting earth, Geophys. J. R. Astron. Soc., 59, 445-462, 1979.

Eguchi, T., S. Uyeda, and T. Maki, Seismotectonics and tectonic history of the Andaman Sea, Tectonophysics, 57, 35-51, 1979

EMSLAB group, The EMSLAB electromagnetic sounding experiment, EOS, Trans., 69, 173-194, 1988.

Ferguson, I. J., F. E. M. Lilley, and J. H. Filloux, Geomagnetic induction in the Tasman Sea and electrical conductivity structure beneath the Tasman Sea floor, Geophys. J. Int., 102, 299-312, 1990.

Filloux, J. H., Oceanic electric currents, geomagnetic variations and deep electrical conductivity structure of the ocean continent transition of
Central California, Ph.D. Thesis, Scripps. Inst. of Oceanogr., Univ. of Calif., San Diego, 1967.

Filloux, J. H., Ocean-floor magnetotelluric sounding over north-central Pacific, Nature, 269, 297-301, 1977.

Fisher, R. A., Statistical Methods for Research Workers, 13th ed., 356 pp., Hafner, New York, 1958.

Heinson, G. S. and F. E. M. Lilley, Thin sheet EM modelling of Tasman Sea, Explor. Geophys., 20, 177-180, 1989.

Hermance, J. F. and G. D. Garland, Deep electrical structure under Iceland, J. Geophys. Res., 74, 3797-3800, 1968.

Jozwick, W. and D. Beamish, A thin sheet model of electromagnetic induction in northern England and southern Scotland, Geophys. J. R. Astron. Soc., 85, 629-643, 1986.

Kumar, M. R., N. Purnachandra Rao, and S. V. Chalam, A seismotectonic study of the Burma and Andaman arc regions using centroid moment tensor data, Tectonophysics, 253, 155-165, 1996.

Lilley, F. E. M., J. H. Filloux, I. J. Ferguson, N. L. Bindoff, and P. J. Mulhearn, The Tasman project of seafloor magnetotelluric exploration: experiment and observation, Phys. Earth Planet. Inter., 53, 405-421, 1989.

Mukhopadhyay, M., Seismotectonics of subduction and backarc rifting under the Andaman Sea, Tectonophysics, 108, 229-239, 1984.

Mukhopadhyay, M., Gravity anomalies and deep structure of the Andaman arc, Mar. Geophys. Res., 9, 197-210, 1988.

Mukhopadhyay, M. and M. R. Krishna, Gravity field and deep structure of the Bengal fan and its surrounding continental margins, northeast Indian Ocean, Tectonophysics, 186, 365-386, 1991.

Pederson, L. B., Relation between potential fields and some equivalent sources, Geophysics, 56, 961-971, 1991.

Peter, G., L. A. Weeks, and R. E. Burns, A reconnaissance geophysical survey in the Andaman Sea and across the Andaman-Nicobar Island arc, J. Geophys. Res., 71(2), 495-509, 1966.

Phoels, K. A. and R. P. Von Herzen, Electrical resistivity structure beneath the northwest Atlantic Ocean, Geophys. J. R. Astron. Soc., 47, 331-347, 1976.

Price, A. T., The induction of electric current in non-uniform thin sheet and shells, Q. J. Mech. Appl. Math., 2, 283-310, 1949.

Price, A. T., The theory of geomagnetic induction, Phys. Earth Planet. Inter., 7, 227-273, 1973.

Rodolfo, K. S., Bathymetry and marine geology of the Andaman basin and tectonic implications for SE Asia, Am. Assoc. Pet. Geol. Bull., 52, 2422-2437, 1969.

Schmucker, U., Anomalies of geomagnetic variations in the southwestern United States, Bull. Scrips. Inst. Oceanogr., 13, 1-165, 1970.

Schmucker, U., Interpretation of induction anomalies above non-uniform surface layers, Geophysics, 36, 156-165, 1971.

Schmucker, U., Electromagnetic induction in thin sheets: integral equations and model studies in two dimensions, Geophys. J. Int., 121, 173190, 1995.

Segawa, J., Y. Hamano, H. Utada, and H. Toh, A sea floor magnetometer model OBM-S4, J. Geod. Soc. Japan, 32, 248-273, 1986.

Shankland, T. J. and H. S. Waff, Partial melting and conductivity anomalies in the upper mantle, J. Geophys. Res., 82, 5409-5417, 1977.

Shimakawa, Y. and Y. Honkura, Electrical conductivity structure beneath the Ryukyu Trench-Arc system and its relation to the Philippine Sea Plate, J. Geomag. Geoelectr., 43, 1-20, 1991.

Treitel, S., W. O. Clement, and R. K. Kaul, The spectral determination of the depths to burried magnetic basement rocks, Geophys. J. R. Astron. Soc., 24, 415-428, 1971.

Vasseur, G. and P. Weidelt, Bimodal electromagnetic induction in nonuniform thin sheet with an application to the northern Pyrenean induction anomaly, Geophys. J. R. Astron. Soc., 51, 445-462, 1977.

Weaver, J. T., Regional induction in Scotland; An example of three dimensional numerical modeling using the thin sheet approximation, Phys. Earth Planet. Inter., 28, 161-180, 1982.

Yukutake, T., J. H. Filloux, J. Segawa, Y. Hamano, and H. Utada, Preliminary report on a magnetotelluric array study in the northwest Pacific, J. Geomag. Geoelectr., 35, 575-587, 1983.

B. Banerjee, P. B. V. Subba Rao (e-mail: srao@iig.iigm.res.in), Gautam Gupta, E. J. Joseph, and B. P. Singh 